\section{KURZ GEMELDET}

Allergy News

\section{Aggressive Tränen}

_ iner 89-jährigen Frau wurden Chlor-

- amphenicol-Augentropfen verordnet. Im Verlauf der folgenden zwei Behandlungswochen kam es zu einer allergischen Konjunktivitis und zu einem periorbitalen Erythem mit Schuppung. Das Aussehen der Haut war charakteristisch für eine schwere Kontaktdermatitis und erstreckte sich auf den Bereich der Wangen, über den üblicherweise die Tränen flossen. Somit musste man eine Auslösung durch die

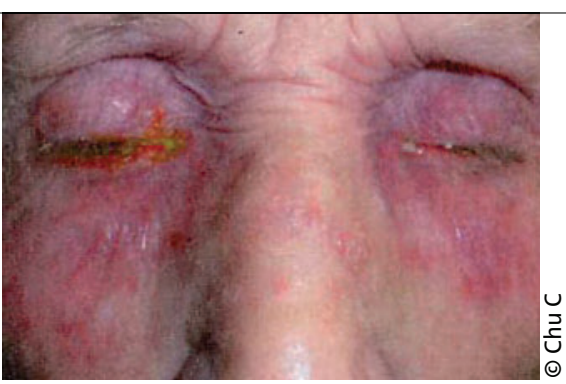

chloramphenicolhaltige Tränenflüssigkeit annehmen. Eine lokale allergische Reaktion gegen Chloramphenicol kommt bei etwa einer von 200 behandelnden Personen vor.

Dr. Hermann S. Füessl

Chu C et al. Brit Med J 2011; 342: d425

\title{
Wärmedämmung mit Nebenwirkungen
}

\begin{abstract}
A $\mathrm{m}$ Thema Wärmedämmung kommt heute kaum noch ein Hausbesitzer vorbei. Dass dabei auch allergologische Gesichtspunkten eine wichtige Rolle spielen können, musste jetzt eine 33-jährige Französin erfahren. Nachdem ihr Haus mit Hanfmatten isoliert worden war, klagte sie über nächtliche Hustenanfälle und Atemnot. Eine allergologische Genese lag nahe, alle Pricktestungen mit klassischen Innenraumallergenen wie Hausstaubmilben oder Schimmelpilzen verliefen aber negativ. Eine heiße Spur ergab sich erst, als die Frau von winzigen Insekten in ihrem Schlafzimmer berichtete. Diese konn-
\end{abstract}

ten als Bücherläuse (Liposcelis sp.) identifiziert werden und tatsächlich war der Pricktest mit einem entsprechenden Extrakt positiv. Auch ließ sich spezifisches IgE nachweisen. Die Läuse leben üblicherweise unter Baumrinden, wo sie sich von Schimmelsporen ernähren. Offensichtlich waren sie zusammen mit dem zu feuchten ökologischen Dämmmaterial ins Haus gelangt. Der Umzug in ein anderes Gebäude brachte die Beschwerden komplett zum Verschwinden.

Perotin JM et al. Allergy 2011 Apr 22; DOI: 10.1111/j.1398-9995.2011.02602.x

\section{Schnelle Schweiß-SIT}

tark juckende Quaddeln, die nach dem Schwitzen auftreten, sind typische Symptome einer cholinergen Urtikaria. Eine erhöhte Prävalenz gibt es in der japanischen Bevölkerung - wo die Erkrankung Sportaktivitäten, Sexualleben und die Kultur heißer Bäder einschränkt. Anders als die Mehrheit der Betroffenen, sprechen schwer Erkrankte auf die übliche Behandlung mit Antihistaminika oft nicht an. Auch alternativ verabreichte Betablocker oder Anti-IgE-Antikörper wirken nicht immer. Japanische Dermatologen überprüften daher Hinweise darauf, dass Allergene im eigenen Schweiß der Patienten zur spezifischen Immuntherapie (SIT) eingesetzt werden können. Zugunsten besserer Compliance wagten sie sich

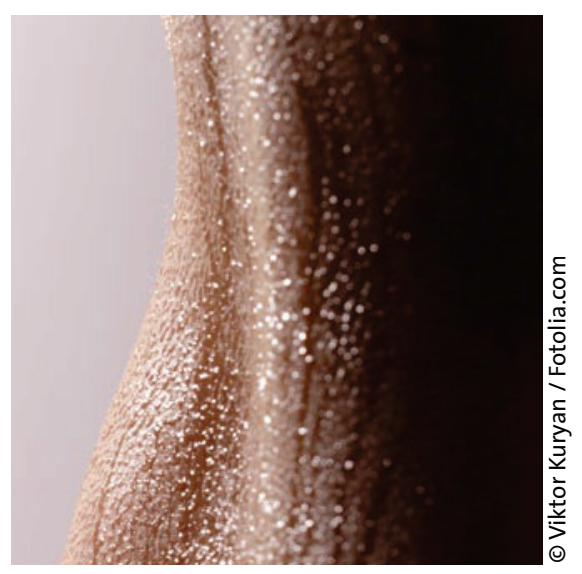

an ein Schnellverfahren. Dazu sammelten sie von sechs Probanden den jeweils eigenen Schweiß und sterilisierten ihn. Anschließend ließen sich die Probanden eine Kochsalzlösung davon nach einem schnellen Aufdosierungsprotokoll subkutan injizieren, eine zwei- bis zwölfmonatige Erhaltungstherapie folgte. Die Bildung von Quaddeln einer Größe von mindestens $6 \mathrm{~mm}$ als Reaktion auf Schweiß war danach bei allen Probanden verzögert und bei fünf (83\%) von ihnen vermindert in Intensität und Frequenz. Bei zwei Probanden $(33 \%)$ war zudem die Histaminfreisetzung reduziert. Systemische Reaktionen traten nicht auf. Als nächster Schritt steht die Charakterisierung des verantwortlichen Antigens an.

we

Kozaru T et al. Allergol Int 2011 Feb 25 [Epub ahead of print] 